https://doi.org/10.5194/acp-2020-303

Preprint. Discussion started: 14 April 2020

(c) Author(s) 2020. CC BY 4.0 License.

\title{
The interaction between urbanization and aerosols during the haze event
}

3 Miao Yu ${ }^{1}$, Guiqian Tang ${ }^{2}$, Yang Yang ${ }^{1}$, Shiguang Miao ${ }^{1}$, Yizhou Zhang ${ }^{1}$, Qingchun $\mathrm{Li}^{1}$

4

5 1. Institute of Urban Meteorology, China Meteorological Administration, Beijing, China

2. State Key Laboratory of Atmospheric Boundary Layer Physics and Atmospheric Chemistry (LAPC), Institute of Atmospheric Physics, Chinese Academy of Sciences, Beijing 100029, China

8

9

21 Corresponding author:

22 Guiqian Tang 
Abstract

The interaction between aerosols and urbanization during the haze event was investigated using the RapidRefresh Multiscale Analysis and Prediction System-Short Term (RMAPS-ST). The mechanisms of the impacts of aerosols and urbanization were also analyzed and quantified. Aerosols reduce urban-related warming during the daytime, and the warming decreased by 30 to $50 \%$ as the concentration of $\mathrm{PM}_{2.5}$ increased from 200 to $400 \mu \mathrm{g} \cdot \mathrm{m}^{-3}$. Aerosols enhance the urban-related warming at dawn, with an increase of approximately $28 \%$, which is important for haze formation. Urbanization reduced the aerosol-related cooling effect by approximately $54 \%$ during the haze event, and the strength of the impact changed little with increasing aerosol content. The impact of aerosols on urban-related warming is more significant than the impact of urbanization on aerosol-related cooling. Aerosols decreased the urban-impact on the mixing layer height by $148 \%$ and on the sensible heat flux by $156 \%$. Furthermore, the aerosols decreased the latent heat flux, and the impact was reduced by $48.8 \%$ by urbanization. The impact of urbanization on the transport of pollutants is more important than that of aerosols. The interaction between urbanization and aerosols may enhance the accumulation of pollution and weigh against diffusion.

\section{Introduction}

In recent years, heavy haze pollution events have occurred more frequently in densely populated urban areas, such as the Beijing-Tianjin-Hebei region (BTH region) and Yangtze River Delta region of China, which has caused increasingly serious adverse effects on transportation, the ecological environment and human health (Zhao et al., 2012; Wu et al., 2010; Liu et al., 2012). A statistical analysis of the variation in haze days in Beijing over the past 10 years shows that the number of haze days has significantly increased (Chen and Wang, 2015; Zhai et al., 2019). The average annual number of haze days was 162 in 1981-1990, 167 in 1991-2000, and 188 in 2001-2010. The conditions for the formation of heavy haze weather in the BTH region are very complex (Miao et al., 2017; Wei et al., 2018; Ren et al., 2019). Atmospheric pollutant emissions, meteorological conditions, terrain, and urban high-density human activities are all important conditions for the formation of heavy haze weather (Zhu et al., 2018). However, meteorological conditions are becoming the most critical conditions for the development of heavy haze pollution weather when there is little change in atmospheric pollutant emissions (Wang et al., 2020; Pei et al., 2020).

The characteristics of the atmospheric boundary layer structure determine the horizontal fluidity, vertical 

affecting the formation, intensity and duration of haze and atmospheric pollution (Guo et al., 2016). Coulter R L. (1979) indicated that the height of the mixing layer would affect the concentration and diffusion of pollutants, which has been one of the most important physical parameters in atmospheric numerical models and atmospheric environment evaluations, and urbanization and aerosols have been proven to influence the boundary layer height (Tao et al., 2015).

Urbanization, as the most drastic means by which human activities transform the environment, has had an important impact on regional climate and weather processes (Miao et al., 2011; Yu and Liu, 2015; Yu et al., 2017). Existing research suggests that there are three main ways by which urbanization influences the climate (Oke, 1982 and 1995). The change with land use from natural surfaces to impervious underlying surfaces in association with urbanization alters the surface albedo and roughness, which results in the formation of urban heat islands (UHIs) (Taha, 1997; Folberth et al., 2014). This leads to a change in the surface energy balance and the form of the thermal difference between urban and rural areas and further changes the boundary layer structure (Grimmond, 2007; Li and Bou-Zeid, 2013). Second, thermal differences further lead to heat island circulation, which can influence the local circulation of synoptics and the transport of pollutants (Crutzen, 2004). Anthropogenic aerosols and heat from the development of transportation and industry are also important parts of urban impacts on climate. However, aerosols can reduce the decrease in shortwave radiation and cause cooling at the surface and enhance static stability, which is opposite to the effects of urbanization (Grimmond, 2007; Cruten, 2004). Furthermore, aerosols may increase longwave radiation in urban areas because they are likely to absorb and emit more energy than water vapor or greenhouse gases under certain conditions (Jacobson,1998; Rudich et al., 2007). There have been few studies on the mechanism of the interaction between urbanization and aerosols, although many studies focus on their respective effects. Accordingly, the interaction between urbanization and aerosols is important for studying regional climate.

Researchers are increasingly aware of the importance of the interaction between urbanization and aerosols. A very important study by Cao et al. 2016 was the first attempt to determine the effects of aerosols on urbanization and indicated that aerosols can increase the nighttime UHI effect using a climate model. Yang et al. 2020 obtained different results when using observational data to perform similar research in the BTH region. 

showed that the combined effect of UHIs and aerosols on precipitation depends on synoptic conditions (Zhong et al., 2015). However, for winter haze, Zhong et al. (2017) evaluated the urban impact on air quality and indicated that urbanization can increase ventilation in daytime and increase aerosol emissions, which outweighs the UHI effect.

However, very few studies have quantified the individual effects of urbanization-induced UHIs and aerosols with elevated emissions on the formation and development of haze in metropolitan areas. A difficulty is that the radiative forcing of aerosols is not a prognostic variable in most climate models (Cao et al. 2016). Some regional models such as WRF-Chem can overcome this problem by parameterizing aerosols to aerosol optical depth (AOD) in some specific radiation schemes. Tao et al. 2015 and Zhong et al. 2018 have made some progress in this area, and their results also indicate that the regional model can be used as an effective way to study the interaction between urbanization and aerosols. However, a quantitative evaluation of urban impacts on aerosols and aerosol impacts on urban-impact at the same time in metropolitan areas has not been attempted.

In this study, the Rapid-Refresh Multiscale Analysis and Prediction System-Short Term (RMAPS-ST) was used to investigate the mechanism of the influence of the above two factors in a typical winter haze event. The objective of this study is 1) to quantify impact of urban on aerosols and impact of aerosols on urbanization respectively and 2) to obtain a better understanding of the interaction between urbanization and aerosols and its influence mechanism on the boundary layer structure and haze transmission during the typical winter haze events in the BTH region. This research will help to improve air quality under the continuous urbanization and sustainable development of large cities.

\section{Methods}

\subsection{Observational data}

Four kinds of observational data were used in this study to reveal the synoptic situation of haze events and perform model evaluation. Meteorological data from 309 national basic weather stations in the BTH region were provided by the China Meteorological Administration (http://data.cma.cn/). The locations of the national basic weather stations are shown in Fig 1 (red dots). The mass concentrations of fine particulate matter $\left(\mathrm{PM}_{2.5}\right)$ were recorded by 251 environmental monitor stations managed by the Ministry of Ecology and Environment 
surface heat flux data were obtained from the Beijing meteorological tower $\left(39.97^{\circ} \mathrm{N}, 116.37^{\circ} \mathrm{E}\right)$, which is $325 \mathrm{~m}$ high and operated by the Institute of Atmospheric Physics (IAP), Chinese Academy of Sciences (CAS). The heat flux data were measured by a fast response eddy covariance sensor system that was sampled at 10 $\mathrm{Hz}$ using CR500 (Campbell Scientific Inc., USA). The radiation data were provided by Kipp \& Zonen (Netherlands) four-component unventilated CNR1 radiometers. Radiation and surface flux data from $140 \mathrm{~m}$ of the tower were used in this study. The mixing layer height (MLH) and backscattering coefficient were measured by enhanced single-lens ceilometers (Vaisala, CL51, Finland) deployed by the IAP. Backscattering coefficient profiles were calculated by reference to the attenuation strobe laser LiDAR technique $(910 \mathrm{~nm})$, which is cited in Tang et al. (2015).

\subsection{Model description and experimental design}

The model used in this study is the latest available version of RMAPS-ST, developed by the Institute of Urban Meteorology, China Meteorological Administration. RMAPS-ST is based on the Weather Research and Forecasting (WRF v3.8.1) model (Skamarock et al., 2008) and its data assimilation system (WRFDA v3.8). The simulation domain was centered at $37.0^{\circ} \mathrm{N}, 105.0^{\circ} \mathrm{E}$ and implemented with two nested grids with resolutions of 9 and $3 \mathrm{~km}$ for two domains (D1 and D2, respectively) (Fig 1a). The model performance was verified and RMAPS-ST runs operationally (Fan et al., 2018). The assimilation began every three hours, and the assimilated data included automatic meteorological station data, sounding data and radar data when available. The model settings are shown in Table 1. The simulation started at 0000 LST and ran from 15 to 23 December 2016 with hourly output.

The urban impact was represented by a high-resolution $(30 \mathrm{~m})$ land use map interpreted from Landsat Thematic Mapper satellite data for 2015 in Beijing. The urban canopy parameters were optimized according to Miao and Chen (2014). The impact of aerosols was represented by adding the hourly distribution of AOD in the RRTMG radiation scheme. The AOD was extracted from the output of RMAPS-Chem (Zhao et al., 2019; Zhang et al., 2018) for the BTH region, which is shown in Fig 1b. Anthropogenic emission data were obtained according to the Multiresolution Emission Inventory for China (2012) (http://www.meicmodel.org/) with a resolution of $0.1^{\circ} \times 0.1^{\circ}$. The simulated distribution of AOD in Beijing has been verified to be satisfactory when compared to the observed vertical profile of the backscattering coefficient (Fig 2a and b). The correlation of AOD and the column backscatter coefficient is 0.76 (Fig 2c). Four tests were designed to investigate the impacts of aerosols and urbanization on typical haze events. Test 1: Both urban and aerosol 

the RRTMG radiation scheme in Domain 2. Test 2: Only aerosol impact was considered in the simulation, and we replaced the urban grid with cropland to shield the impact of urbanization. Test 3: Only urban impact was considered, and the direct radiative forcing of aerosols was not considered in the simulation. Test 4: Both urban and aerosol impacts were not considered in the simulation.

The model evaluation results for the four tests are shown in Table 2. As the service operational system, the RMAPS-ST model assessment report indicated that the model performance was satisfactory (Fan et al. 2018). We evaluated not only the conventional meteorological variables (including temperature, humidity and wind speed) but also unconventional but important variables for this study (including radiation and surface heat flux). A total of 309 meteorological station data points were used to evaluate the conventional variables. The unconventional variables were evaluated according to the observational data from $140 \mathrm{~m}$ of the Beijing meteorological tower. Test 1 was found to be the best simulation and considers both the urban and aerosol impacts.

\section{Results}

\subsection{Weather analysis}

A typical continuous severe heavy haze occurred from the $15^{\text {th }}$ to $22^{\text {nd }}$ of December 2016 in the BTH region. Three stages dominated by three different synoptic patterns controlled the formation of this haze. In the first stage, northwest airflow in front of a ridge of high pressure was observed in the BTH region at a height of 700 to $500 \mathrm{hPa}$ and in eastern China at a height of $850 \mathrm{hPa}$ on the $15^{\text {th }}$ to $16^{\text {th }}$ of December, which induced a sharp warming pattern (Fig 3a and b). At the surface, Beijing was located under the front of the high pressure system to under the southwest airflow in front of the low pressure system (Fig 4), which favored pollutant transport from Hebei Province to Beijing. From the $17^{\text {th }}$ to the night of the $18^{\text {th }}$, the control system turned to the latitude circulation at 700 to $500 \mathrm{hPa}$ over the BTH region (there was a trough line south of $40^{\circ} \mathrm{N}$ at $2000 \mathrm{LST}$ on the $17^{\text {th }}$ and $\left.18^{\text {th }}\right)$ (Fig 3c). There was a northwest wind located north of $40^{\circ} \mathrm{N}$ and a southwest wind located south of $40^{\circ} \mathrm{N}$ at $850 \mathrm{hPa}$ (Fig 3d). The near surface was controlled by the northeast airflow located in the inverted trough of the low pressure. The weak convergence of the high trough cooperates with the low pressure at the surface, leading to continuous pollution accumulation near the surface. Under this weather situation, the nearsurface temperature began to continuously increase from the $16^{\text {th }}$ to $18^{\text {th }}$, and the specific humidity also correspondingly increased (Fig 5a). The near-surface wind speed and pressure decreased during this period 
(Fig 5b). The concentration of $\mathrm{PM}_{2.5}$ gradually increased from the $16^{\text {th }}$, and the average concentration of $\mathrm{PM}_{2.5}$ reached $200 \mu \mathrm{g} \cdot \mathrm{m}^{-3}$ on the $18^{\text {th }}$. The density of ozone obviously decreased from the $16^{\text {th }}$ (Fig $5 \mathrm{c}$ ).

The MLH significantly declined from the $16^{\text {th }}$, and the diurnal circle almost disappeared during this period, accompanied by a visibility reduction but diurnal variation (Fig $5 \mathrm{~d}$ ). The downward shortwave radiation and the net radiation gradually decreased from the $16^{\text {th }}$ to the $18^{\text {th }}$, which directly influenced the variation trend of ozone (the maximum density of ozone was less than $110 \mathrm{mg} \cdot \mathrm{m}^{-3}$ ), while there was little change detected in longwave radiation (Fig 5e). The observed sensible heat flux also decreased from the $16^{\text {th }}$ to the $19^{\text {th }}$ although the temperature increased, which means that the heat exchange became weaker in the vertical direction, while the latent heat flux changed little (Fig 5f). Southwest airflow was again captured by a wind profiler on the night of the $18^{\text {th }}$ and the transport layer occurred from 300 to $1500 \mathrm{~m}$, which differs from the previous surface transport pattern (Fig 4).

In the second stage, the important change occurred in the morning of the $19^{\text {th }}$ of December, when the control system turned to the northwest airflow on the front of the trough over the $\mathrm{BJH}$ region at 500 to $850 \mathrm{hPa}$ (Fig $3 \mathrm{e}$ and f). After $2000 \mathrm{LST}$ on the $19^{\text {th }}$, obvious warming occurred again at $850 \mathrm{hPa}$ in eastern China (Fig 3h). However, the near-surface maximum temperature and diurnal range in Beijing significantly decreased but with high specific humidity during the $20^{\text {th }}$ to the $21^{\text {st }}$ (Fig 5a). According to the surface weather map, the control system turned to the southwest at 1400 LST on the $19^{\text {th }}$, and a large-scale southeast wind appeared in eastern Beijing after 2000 LST, which induced wide advection fog formation during the night (Fig 3g). Due to the influence of the southwest airflow on the tough at $500 \mathrm{hPa}$, the inverted trough moved east, and Beijing was located in the southeast wind zone. The near-surface pressure increased slightly, and the wind speed remained low at approximately $1 \mathrm{~m} \cdot \mathrm{s}^{-1}$ (Fig $5 \mathrm{~b}$ ). The synoptic system caused the $\mathrm{PM}_{2.5}$ concentration to peak (approximately $400 \mu \mathrm{g} \cdot \mathrm{m}^{-3}$ on average and above $500 \mu \mathrm{g} \cdot \mathrm{m}^{-3}$ observed at some stations) and was maintained from the $20^{\text {th }}$ to the $21^{\text {st }}$ in the BTH region. The visibility was less than 400 meters, and the diurnal circle disappeared (Fig $5 \mathrm{~d}$ ). The decrease in the downward shortwave and net radiation was more pronounced than that in the previous three days (Fig 5e). The sensible heat flux also decreased, and the diurnal circle almost disappeared from the $19^{\text {th }}$ to the $20^{\text {th }}$ (Fig 5e).

It was not until the strong cold air moved southward in the early morning of the $22^{\text {nd }}$ when the whole atmosphere converted to the northwest stream. The air pollutants were completely removed in the third stage. 


\subsection{Interaction between the impacts of urbanization and aerosols on haze events}

Four impacts were analyzed as following. Urban impact under the aero scenario (UI_aero) was represented by the results of Test 1 minus those of Test 2; urban impact under the no-aero scenario (UI_noaero) was represented by the results of Test 3 minus those of Test 4; The impact of the urbanization scenario was represented by the results of Test 1 minus those of Test 3 (AI_urban); the impact without urbanization was represented by the results of Test 2 minus those of Test 4 (AI_nourban). The interaction between urbanization and aerosols on local meteorological and regional transportation was discussed.

\subsubsection{The impact on the local area}

Temperature is one of the most sensitive variables affected by urbanization and aerosols and is also the most concerning variable. The impact of urbanization on the near-surface temperature in the Beijing area displays diurnal variation features. The warming induced by urbanization was dominant at night. The urban impact was obviously decreased under the aerosol scenario by comparing the results of UI_aero and UI_noaero, especially in the daytime (Fig 6a, red lines). The urban impact always showed a positive contribution to the temperature during the whole day under the no-aerosol scenario, while the urban impact became slightly negative with the aerosol scenario in the daytime. The maximum difference between UI_aero and UI_noaero occurred on the $20^{\text {th }}$ and $21^{\text {st }}$, when the AOD value reached its maximum, and the difference almost disappeared on the $15^{\text {th }}$ and $22^{\text {nd }}$, with a small AOD (Fig 2b). The results indicate that the impact of urbanization on temperature is reduced by aerosols, which is consistent with the findings of Yang et al. 2020 . The average urban impact on temperature in Beijing during the $16^{\text {th }}$ to $19^{\text {th }}$ with a $\mathrm{PM}_{2.5}$ concentration of approximately $200 \mathrm{mg} \cdot \mathrm{m}^{-3}$ was a reduction of $0.42^{\circ} \mathrm{C}$ according to UI_aero and of $0.60^{\circ} \mathrm{C}$ according to UI_noaero. This means that aerosols reduce the urban impact on temperature by $30 \%$. When the concentration of $\mathrm{PM}_{2.5}$ reached $500 \mathrm{mg} \cdot \mathrm{m}^{-3}$ from the $20^{\text {th }}$ to the $21^{\text {st }}$, the aerosols reduced urbanization-related warming by $53.5 \%$.

The impact of aerosols on temperature is negative and without a diurnal circle under the urbanization scenario for the whole day (Fig 6a, blue lines). However, the impact of aerosols captured by AI_nourban is more significant and displays a diurnal circle. Another important observation is that the impact of aerosols on temperature under the no-urban scenario is not always negative. There is a slight warming period at dawn in the AI_nourban scenario, which maybe because the longwave radiation is increased (Jacobson,1998; Rudich 
et al., 2007). The average impact of aerosols on temperature in Beijing was $-0.16^{\circ} \mathrm{C}$ with urbanization and $0.34^{\circ} \mathrm{C}$ without urbanization from the $16^{\text {th }}$ to the $19^{\text {th }}$. The impact of aerosols was $-0.19^{\circ} \mathrm{C}$ with urbanization and $-0.43^{\circ} \mathrm{C}$ from the $20^{\text {th }}$ to the $21^{\text {st }}$. Urbanization decreased the impact of aerosols by $53 \%$ under moderate pollution and by up to $56 \%$ under heavy pollution. Two different impacts of aerosols on urban-related warming were observed. There was a reducing effect in the daytime with a strength of approximately 30 to $50 \%$ of the concentration and an increasing effect occurred at dawn with a strength of approximately $28 \%$. Urbanization reduced the aerosol-related cooling effect by approximately $54 \%$.

The observed specific humidity continued to increase as the aerosol concentration increased (Fig 5b) and is closely related to the UHI effect and aerosol composition (Zhang et al. 2010; Sun et al., 2013; Wang et al., 2020). The specific humidity also increased with urbanization throughout the day (Fig 6b, red lines). Similar to temperature, urbanization had a more pronounced impact on specific humidity at night. The average urban impact on specific humidity was $0.0366 \mathrm{~g} \cdot \mathrm{kg}^{-1}$ according to UI_aero and $0.0478 \mathrm{~g} \cdot \mathrm{kg}^{-1}$ according to UI_noaero during the $16^{\text {th }}$ to $19^{\text {th }}$ and 0.0308 and $0.0448 \mathrm{~g} \cdot \mathrm{kg}^{-1}$ during the $20^{\text {th }}$ to $21^{\text {st }}$. Aerosols not only reduced the urban impact on the average daily specific humidity by $23.43 \%$ but also reduced the diurnal range of specific humidity.

In contrast to urbanization, aerosols were found to reduce the specific humidity (Fig $6 \mathrm{~b}$, blue lines). The impact of aerosols under the urbanization scenario was small and without a diurnal pattern. However, their impact under the no-urban scenario was more distinct and with a diurnal circle. The average impact of aerosols on specific humidity was $-0.0088 \mathrm{~g} \cdot \mathrm{kg}^{-1}$ according to AI_urban and $-0.0136 \mathrm{~g} \cdot \mathrm{kg}^{-1}$ according to AI_nourban during the whole study period. Urbanization reduced the impact of aerosols on specific humidity by $35.3 \%$. The impacts of urbanization and aerosols on humidity were slightly greater than those of aerosols on urban impacts.

There was no effect of urbanization on downward shortwave radiation according to both UI_aero and UI_noaero (Fig 6c, red lines), although the value is not absolutely related to aerosols because of model uncertainty. Aerosols reduce the downward shortwave radiation in the daytime, and there are few differences between AI_urban and AI_nourban.

The average decrease in shortwave radiation caused by aerosols was approximately $7 \%$ of the total downward 
shortwave radiation during the $16^{\text {th }}$ to the $20^{\text {th }}$ and up to $17 \%$ when the $\mathrm{PM}_{2.5}$ was greater than $400 \mu \mathrm{g} \cdot \mathrm{m}^{-3}$. The urban impact increased the longwave radiation in the nighttime according to UI_aero, while the impact of urbanization was always positive for longwave radiation during the study period according to UI_noaero (Fig 6d, red lines). Because it is closely related to temperature, the urban impact on long wave radiation was also reduced by aerosols, with reductions of $83.3 \%$ from the $16^{\text {th }}$ to the $19^{\text {th }}$ and of $96.6 \%$ from the $20^{\text {th }}$ to the $21^{\text {st }}$. The impact of aerosols on longwave radiation is smaller than that of shortwave radiation, and there was a slight decrease captured by AI_urban with an increase from noon on the $20^{\text {th }}$ to nighttime on the $21^{\text {st }}$. The impact of aerosols decreased the longwave radiation captured by AI_nourban during the $16^{\text {th }}$ to the $20^{\text {th }}$ and increased it on the night of $21^{\text {st }}$ (Fig $6 \mathrm{~d}$, blue lines). Urbanization reduced the impact of aerosols on longwave radiation by $66.9 \%$ while aerosols reduced the urban impact on longwave radiation by $89.2 \%$. The impacts of urbanization and aerosols on longwave radiation are unimportant because they are both smaller than $2 \mathrm{~W} \cdot \mathrm{m}^{-}$ 2

The change in radiation further alters the MLH. Previous studies suggest that MLH is important for the diffusion of pollutants and haze formation (Sun et al. 2013; Quan et al. 2014). Previous studies on urbanization indicated that urban-induced warming will increase the MLH during the daytime (Wang et al., 2007; Miao et al. 2012), and the results of UI_noaero show the same pattern. However, when we introduced aerosols into the simulation, urbanization was found to decrease the MLH in the daytime according to UI_aero. The impact of aerosols decreased the average urbanization by $148 \%$ during the haze event (Fig 6e, red lines). Aerosols significantly decreased the MLH in daytime according to both AI_urban and AI_nourban (Fig 6e, blue lines). Urbanization decreased the impact of aerosols on MLH by $57.84 \%$ during the haze event.

Urban land use change directly alters the surface heat flux. Urbanization increased the sensible heat flux according to UI_noaero but decreased the sensible heat flux according to UI_aero (Fig 6f, red lines). The impact of aerosols in reducing the urban impact on sensible heat flux was $156 \%$ during the haze event. Aerosols reduced the sensible heat flux according to both AI_urban and AI_nourban (Fig 6f, blue lines). The maximum impact of aerosols was on the $21^{\text {st }}$, with the maximum AOD. The impact of urbanization reduced the impact of aerosols on sensible heat flux by $59.3 \%$.

There was little effect of urbanization on latent heat flux because the observed latent heat flux in urban areas was small (Fig 6g, red lines, and Fig 5e). Aerosols decreased the latent heat flux, and the impact increased 
with increasing AOD (Fig 6g, blue lines). The impact of urbanization reduced the impact of aerosols on the latent heat flux by $48.8 \%$.

In general, the impact of aerosols on urban impacts is more important than the impact of urban impacts on aerosol impacts in terms of local effects.

\subsubsection{Effects on regional circulation}

There are few valuable findings from the diurnal average wind speed analysis because the average wind speed was low during the haze event. Wind speed is likely to become more meaningful in the spatial analysis of wind vectors. There are two main transmission processes of pollution from Hebei Province to Beijing in this haze process according to the weather map and wind profile analysis (Fig 4). Accordingly, the diurnal pattern of $\mathrm{PM}_{2.5}$ in Beijing (Fig 5c) also displays two increasing processes on the $16^{\text {th }}$ and $19^{\text {th }}$ (from 1800 to 2400 LST). The observed near-surface wind vector displays these two pollutant transport processes (Fig 7). In the first processes, obvious aerosol transport began on the night of the $15^{\text {th }}$ and continued to the night of the $16^{\text {th }}$ (Fig 6). The southwest wind dominated most of the southern part of Hebei Province. The transmission flux was strong in the daytime on the $16^{\text {th }}$, leading to the concentration of $\mathrm{PM}_{2.5}$ continuing to increase in Beijing and in its transmission path. The wind speed remained low from the $17^{\text {th }}$ to the $18^{\text {th }}$ in most of the plain area, and the concentration of $\mathrm{PM}_{2.5}$ continued to increase in the southwest and northeast of Hebei Province. The second processes began at 1400 LST on the $19^{\text {th }}$ and the south wind dominated the south of Beijing and turned to the southwest in Beijing at 1400 to 1800 LST. The dominant wind direction turned to the southwest at 2200 LST in the southern part of Hebei Province with a rapid increase in the concentration of $\mathrm{PM}_{2.5}$.

Most industrial aerosols in Beijing are transported from the southwest and northeast of Hebei Province due to the control of pollutant discharge in the Beijing area during haze events. Therefore, the impact of urban areas and aerosols on transport, namely wind fields is very important for air quality in Beijing. The modeling results show that urbanization not only increased the temperature in urban areas (Fig 8a and b) but also increased the average south-wind transport flux in the two main transmission processes of pollution in the southwest area of Beijing (Fig 8a and b). The transmission flux captured by UI_noaero is stronger than that captured by UI_aero. The local cyclonic circulation induced by urbanization further induces upward movement, which is beneficial to diffusion conditions. Although aerosols decrease the transmission flux induced by urbanization, the strength of local cyclonic circulation is also reduced by aerosols. Furthermore, the aerosols reduced the 

aerosols on temperature. There was no local or systemic effect on the wind field captured by either AI_urban or AI_nourban.

Taylor diagrams were used to analyze the relative contributions of urbanization and aerosols over time (Fig 9). The daily mean difference in these four types of impact (UI_aero, UI_noaero, AI_urban, and AI_nourban) over the eight days in the Beijing area is shown by Taylor diagrams. UI_noaero shows that temperature continues increasing from Day 1 to Day 5 and reaches a maximum on Day 7. The variation in temperature according to UI_urban is smaller. This means that the effect of urbanization on temperature is decreased by aerosols. Temperature increases from Day 1 to Day 7 according to AI_urban, while AI_nourban shows an increase from Day 3 to Day 7. The reduction of the urban impact on temperature by aerosols was more important than the reduction of aerosol impact on temperature by urbanization (Fig 9a). The effect of aerosols on urban impacts on temperature was more important than urban impacts on the effects of aerosols on temperature (Fig 9a). Specific humidity continued increasing from Day 1 to Day 5 according to UI_noaero, while the variation in specific humidity was small according to UI_aero (Fig 9b). Similar to what was observed for temperature, reducing the urban impact on specific humidity by aerosols is more important than reducing aerosol impacts by urban areas. The ventilation coefficient (VC) in UI_aero showed little change over these eight days, and this coefficient showed increases on Days 2, 3, 5, and 6 and decreases on Days 4, 7, and 8 according to UI_noaero. The reduction of the urban impact on the $\mathrm{VC}$ by aerosols is more important than the reduction of the impact of aerosols by urbanization. The analysis of shortwave radiation also provided the same conclusion that the reduction in the urban impact on the daily mean by aerosols was more important than the reduction of the impact of aerosols by urbanization (Fig 9d).

\subsubsection{Impacts on the vertical distribution}

In the period from $0000 \mathrm{LST}$ to $0800 \mathrm{LST}$ on the $16^{\text {th }}$ to $20^{\text {th }}$, there was an interesting phenomenon that temperature was a slightly larger in UI_aero than in UI_noaero, and the urban impact reached a maximum at the same time. Such an outcome is easy to overlook if the analysis only focuses on the daily average. Therefore, a detailed vertical temperature and wind field analysis of the four addressed scenarios (UI_aero, UI_noaero, AI_urban, and AI_nourban) was used to determine the mechanism behind this finding (Fig 10). 
Aerosols not only increased the warming impact induced by urbanization but also reduced the warming height. Aerosols increase the near-surface warming effect induced by urbanization because of the absorption of longwave radiation. Although absorption by aerosols was always observed during the study period, the impact increased with the increase in longwave radiation induced by urbanization. Therefore, the warming effect of aerosols may dominate at night in the near-surface layer. This further induces the urban-related warming to increase and compress this effect to a lower height with a lower MLH in UI_aero than in UI_noaero (Fig 10a). The aerosols reduced the temperature below $450 \mathrm{~m}$ in the urban area of Beijing (Fig 10c and d) and the cooling effect was reduced by urbanization below $450 \mathrm{~m}$. Urbanization also reduces the near-surface west wind induced by aerosols in urban areas because of the drag caused by buildings.

\section{Conclusion}

A typical persistent haze process occurred on the $15^{\text {th }}$ to $22^{\text {nd }}$ of December 2016 in the BTH region. The average concentration of $\mathrm{PM}_{2.5}$ was approximately $200 \mu \mathrm{g} \cdot \mathrm{m}^{-3}$ and the maximum was greater than $400 \mu \mathrm{g} \cdot \mathrm{m}^{-}$ ${ }^{3}$. The interaction between aerosols and urbanization on haze events were investigated in this study. Four tests were designed using RMAPS-ST to study the mechanism of the impacts of aerosols and urbanization respectively.

Two different impacts of aerosols on urban-related warming were found. A reducing effect occurred during the daytime, and the strength was approximately 30 to $50 \%$ of the concentration. An increasing effect occurred at dawn, and the strength was approximately $28 \%$, which is important for haze formation. The combined effect was a reducing effect on the daily mean of urban-related warming. Urbanization reduced the aerosol-related cooling effect by approximately 54\% during the haze event, and the strength of the impact changed little with increasing aerosol content. The impact of urbanization on the effect of aerosols on humidity is slightly larger than the impact of aerosols on urban impact. Aerosols reduce the average downward shortwave radiation from $7 \%$ to $17 \%$ with concentrations of $\mathrm{PM}_{2.5}$ of 200 to $400 \mu \mathrm{g} \cdot \mathrm{m}^{-3}$. There is no urban impact on downward shortwave radiation or the impact of aerosols on shortwave radiation. The impacts of urban areas and aerosols on longwave radiation are both smaller than $2 \mathrm{~W} \cdot \mathrm{m}^{-2}$. A more significant impact of aerosols is on the MLH and sensible heat flux. The decrease in urban impact caused by aerosols reaches $148 \%$ for MLH and 156\% for sensible heat flux. These values are much larger than those for urbanization, which reduces the impact of aerosols on the MLH and sensible heat flux. There is little urban impact on latent heat flux. However, aerosols decreased the latent heat flux, and the impact was reduced by $48.8 \%$ by urbanization. In general, the impact 
of aerosols on urban impact is more important than the impact of urbanization on aerosol impacts in terms of regional averages.

Urbanization increased the wind speed southwest of the Beijing area and the local cyclonic circulation in the urban area of Beijing during the two main transmission processes. Although aerosols reduced the urban-related southwest transmission, they made the diffusion conditions worse in urban areas. The impact of urbanization on wind fields, namely, the transport of pollutants, is more important than that of aerosols. However, the interaction between urbanization and aerosols may enhance the accumulation of pollution and weigh against diffusion.

The impact of aerosols on urban-related warming is more significant than the impact of urbanization on aerosol-related cooling according to spatial statistical analysis. Similar results were found for absolute humidity, the VC and shortwave radiation. Aerosol-related warming is dominant at dawn in the near-surface layer. Aerosols increase urban-related warming and reduce the impact height of urban-related warming. This further enhances stability and reduces the MLH.

In this study, it was easier to distinguish the impacts of aerosols and urbanization by using the RMAPS-ST with AOD hourly input than with RMAPS-Chem to investigate the impact of aerosols. One reason for this is that the model performance of RMAPS-ST is much better than that of RMAPS-Chem in meteorological fields. Although real-time feedback in modeling is not provided, RMAPS-ST is more efficient and more suitable for short-term operational forecasting.

\section{Data availability}

The data in this study are available from the corresponding author upon request (tgq@dq.cern.ac.cn).

\section{Author contribution}

Miao Yu designed the research and wrote the paper. Guiqian Tang conducted the measurements and reviewed the paper. Yang Yang conducted modelling tests. Qingchun Li did synoptic analysis. Shiguang Miao and Yizhou Zhang reviewed and commented on the paper. 


\section{Competing interests}

430 The authors declare that they have no conflicts of interest to disclose.

431

432

433

Table 1 RMAPS-ST model settings.

\begin{tabular}{ccc}
\hline WRF v3.8.1 & D01 & D02 \\
\hline Horizontal grid & $649 \times 400$ & $550 \times 424$ \\
Grid horizontal spacing $(\mathrm{km})$ & 9 & 3 \\
Vertical layers & 49 & YSU (Hong et al., 2006) \\
PBL & Thompson (Thompson et al., 2008) \\
Microphysics & Kain-Fritsch (Kain, 2004) \\
Cumulus & RRTMG \\
LW Radiation & RRTMG \\
SW Radiation & Noah LSM+SLUCM \\
LSM & Modified according to Miao and Chen (2014) \\
\hline Urban parameter values
\end{tabular}

434

435

Table 2 Model evaluation (RMSE and BIAS) for the four tests.

\begin{tabular}{ccccccccc}
\hline & \multicolumn{2}{c}{ Test 1 } & \multicolumn{2}{c}{ Test 2 } & \multicolumn{2}{c}{ Test 3 } & \multicolumn{2}{c}{ Test 4 } \\
\cline { 2 - 8 } & RMSE & BIAS & RMSE & BIAS & RMSE & BIAS & RMSE & BIAS \\
\hline Temperature & $\mathbf{1 . 2 7}$ & $\mathbf{0 . 3 5}$ & 1.45 & -0.73 & 2.12 & 1.04 & 1.78 & -0.45 \\
Specific humidity & $\mathbf{0 . 2 6}$ & $\mathbf{- 0 . 0 1 5}$ & 0.31 & 0.019 & 0.34 & -0.05 & 0.29 & 0.03 \\
Wind speed & $\mathbf{1 . 6 2}$ & $\mathbf{0 . 9 7}$ & 2.08 & 1.68 & 1.85 & 1.04 & 1.96 & 1.67 \\
Shortwave & $\mathbf{4 0 . 9 1}$ & $\mathbf{1 1 . 8 5}$ & 40.95 & 11.89 & 47.35 & 17.45 & 46.26 & 16.45 \\
Longwave & $\mathbf{5 1 . 3 9}$ & $\mathbf{- 4 3 . 6 5}$ & 51.32 & -44.45 & 51.24 & $\mathbf{- 4 3 . 5 3}$ & 52.76 & 44.97 \\
Sensible heat flux & $\mathbf{8 . 0 9}$ & $\mathbf{- 1 . 1 9}$ & 9.13 & -3.92 & 9.34 & -3.43 & 12.3 & -6.17 \\
Latent heat flux & $\mathbf{1 4 . 0 9}$ & $\mathbf{- 5 . 7 5}$ & 14.52 & -5.95 & 14.85 & -5.87 & 16.76 & -6.23 \\
\hline
\end{tabular}




\section{References}

Cao, C., Lee, X., Liu, S., Schultz, N., Xiao, W., Zhang, M., and Zhao, L.: Urban heat islands in China enhanced by haze pollution, Nature Communications, 7(1), 1-7, 2016.

Chen, H., and H. Wang: Haze Days in North China and the associated atmospheric circulations based on daily visibility data from 1960 to 2012, J. Geophys. Res. Atmos., 120, 5895-5909, 2015.

Coulter, R.L.: A Comparison of three methods for measuring mixing-layer height. J Appl Meteor,18(11):1495-1499, 1979.

Crutzen, P. J.: New directions: the growing urban heat and pollution 'island' effect-impact on chemistry and climate, Atmos. Environ, 38, 3539-3540, 2004.

Fan, S.: Assessment report of regional high resolution model (RMAPS-ST), IUM Technical Note IUM/2018-1, Beijing, China: IUM, 2018.

Folberth, G. A., Rumbold, S. T., Collins, W. J., and Butler, T. M.: Global radiative forcing and megacities. Urban Clim., 1, 4$19,2014$.

Grimm, N. B. et al.: Global change and the ecology of cities, Science 319, 756-760, 2008.

Grimmond, C.S. B., Kuttler, W., Lindqvist, S., and Roth, M.: Urban climatology icuc6, International Journal of Climatology, 27(14), 1847-1848, 2010.

Grimmond, S.U. E.: Urbanization and global environmental change: local effects of urban warming, Geographical Journal, 173(1), 83-88, 2007.

Guo, J., Miao, Y., Zhang, Y., Liu, H., Li, Z., Zhang, W., ...and Zhai, P.: The climatology of planetary boundary layer height in China derived from radiosonde and reanalysis data. Atmos. Chem. Phys, 16(20), 13309-13319, 2016.

Hong, S. Y., Noh, Y., and Dudhia, J.: A new vertical diffusion package with an explicit treatment of entrainment processes, Monthly Weather Review, 134, 2318-2341, 2006.

Jacobson, M. Z.: Studying the effects of aerosols on vertical photolysis rate coefficient and temperature profiles over an urban airshed, J. Geophys. Res, 103,10593-10604, 1998.

Kain, J. S.: The Kain-Fritsch convective parameterization: An update, Journal of Applied Meteorology, 43, 170-181, 2004.

Li, D. and Bou-Zeid, E.: Synergistic interaction between urban heat islands and heat waves: the impact in cities is larger than the sum of its parts, J. Appl. Meteorol. Climatol, 52, 2051-2064, 2013.

Liu, Q., Geng, H., Chen Y.: Vertical distribution of aerosols during different intense dry haze period around Shanghai, China Environmental Science (in Chinese), 32(2), 207-213, 2012.

Miao, S, Dou J., Chen, F., Li, J., and Li A.: Analysis of observations on the urban surface energy balance in Beijing, Science China Earth Sciences, 055(11), 1881-1890, 2012.

Miao, S. and Chen, F.: Enhanced modeling of latent heat flux from urban surfaces in the Noah/single-layer urban canopy coupled model, Science China Earth Sciences, 057(10), 2408-2416, 2014.

Miao, S., Chen, F., Li, Q., and Fan, S.: Impacts of urban processes and urbanization on summer precipitation: A case study of heavy rainfall in Beijing on 1 August 2006, Journal of Applied Meteorology and Climatology, 50, 806-825, https://doi.org/10.1175/2010JAMC2513.1, 2011

Miao, Y., Guo, J., Liu, S., Liu, H., Li, Z., Zhang, W., and Zhai, P.: Classification of summertime synoptic patterns in Beijing and their associations with boundary layer structure affecting aerosol pollution., Atmos. Chem. Phys, 17(4), 3097-3110, 2017.

Oke, T.R.: The energetic basis of the urban heat island, Quarterly Journal of the Royal Meteorological Society, 108, 1-24, 1982.

Oke, T.R.: The heat island of the urban boundary layer: Characteristics, causes and effects, Wind Climate in Cities, 81-107, 1995.

Pei, L., Yan, Z., Chen, D., \& Miao, S.: Climate variability or anthropogenic emissions: which caused Beijing Haze? Environmental Research Letters, 15(3), 034004, 2020. 
Quan, J., Tie, X., Zhang, Q., Liu, Q., Li, X., and Gao, Y., et al.: Characteristics of heavy aerosol pollution during the 20122013 winter in Beijing, China, Atmospheric Environment, 88(Complete), 83-89, 2014.

Ren, Y., Zhang, H., Wei, W., Wu, B., Cai, X., and Song, Y.: Effects of turbulence structure and urbanization on the heavy haze pollution episodes, Atmospheric Chemistry and Physics, 19. 1041-1057. 2019.

Rudich, Y., Donahue, N. M. \& Mentel, T. F. Aging of organic aerosol: bridging the gap between laboratory and field studies, Ann. Rev. Phys. Chem., 58,321-352, 2007.

Skamarock, W. C., Klemp, J. B., Dudhia, J., Gill, D. O., Barker, D., Wang, W., and Powers, J. G.: A description of the advanced research WRF version 3, NCAR/TN-475 + STR, 2008.

Sun, Y., Wang, Z., Fu, P., Jiang, Q., Yang, T., Li, J., \& Ge, X.: The impact of relative humidity on aerosol composition and evolution processes during wintertime in Beijing, China, Atmospheric Environment, 77, 927-934, 2013.

Taha, H.: Urban climates and heat islands: albedo, evapotranspiration, and anthropogenic heat, Energy Build., 25, 99-103, 1997.

Tang, G., Zhu, X., Hu, B., Xin, J., and Wang, Y.: Impact of emission controls on air quality in beijing during apec 2014: lidar ceilometer observations, Atmospheric Chemistry and Physics, 15(21), 12667-12680, 2015.

Tao, W., Liu, J., Ban-Weiss, G. A., Hanglustaine, D. A., Zhang, L., Zhang, Q., et al.: Effects of urban land expansion on the regional meteorology and air quality of eastern China, Atmospheric Chemistry and Physics, 15(15), 8597-8614, https://doi.org/10.5194/acp-15-8597-2015, 2015.

Thompson, G., Field, P. R., Rasmussen, R. M., \& Hall, W. D.: Explicit forecasts of winter precipitation using an improved bulk microphysics scheme. Part II: Implementation of a new snow parameterization. Monthly Weather Review, 136, 5095$5115,2008$.

Wang, K., Wang, J., Wang, P., Sparrow, M., Yang, J., Chen, H.: Influences of urbanization on surface characteristics as derived from the Moderate-Resolution Imaging Spectroradiometer: A case study for the Beijing metropolitan area, Journal of Geophysical Research, 112 (D22), doi:10.1029/2006jd007997, 2007.

Wang, Y., Yu, M., Wang, Y., Tang, G., Song, T., Zhou, P., ... and Zhu, X.: Rapid formation of intense haze episodes via aerosolboundary layer feedback in Beijing. Atmospheric Chemistry and Physics, 20(1), 45-53, 2020.

Wei, W., Zhang, H., Wu, B., Huang, Y., Cai, X., Song, Y., and Li, J.: Intermittent turbulence contributes to vertical dispersion of PM2:5 in the North China Plain: cases from Tianjin, Atmos. Chem. Phys., 18, 12953-12967, https://doi.org/10.5194/acp18- 12953-2018, 2018.

Wu, D., Wu, X, Li, F., et al.: Temporal and spatial variation of haze during 1951-2005 in Chinese mainland, Acta Meteorolgica Sinica (in Chinese),68(5),680-688,2010.

Xu, X., Chen, F., Barlage, M., Gochis, D., Miao, S., and Shen, S.: Lessons learned from modeling irrigation from field to regional scales, Journal of Advances in Modeling Earth Systems, 11, 2428-2448, https://doi.org/10.1029/2018MS001595, 2019.

Yang, Y., Zheng, Z., Yim, S. Y. L., Roth, M., Ren, G., Gao, Z., et al.: PM2.5 pollution modulates wintertime urban heat island intensity in the Beijing - Tianjin - Hebei Megalopolis, China. Geophysical Research Letters, 47, e2019GL084288. https://doi.org/10.1029/2019GL084288., 2020.

Yu, M., and Y. Liu: The possible impact of urbanization on a heavy rainfall event in Beijing, J. Geophys. Res. Atmos., 120, 8132-8143, doi:10.1002/2015JD023336, 2015.

Yu, M., Miao, S., and Li, Q.: Synoptic analysis and urban signatures of a heavy rainfall on 7 August 2015 in Beijing. Journal of Geophysical Research: Atmospheres, 122, 65-78, https://doi.org/10.1002/2016JD025420, 2017.

Yu, M., Y. M. Liu, Y. F. Dai, et al.: Impact of urbanization on boundary layer structure in Beijing, Climatic Change, 120(12), 123-136, 2013.

Zhai, S.X, Jacob, Daniel Wang, Xuan, Shen, Lu \& Li, Ke \& Zhang, Yuzhong \& Gui, Ke \& Zhao, Tianliang \& Liao, Hong.: Fine particulate matter (PM2.5) trends in China, 2013-2018: contributions from meteorology, Atmospheric Chemistry and 
Physics, 19(16), 11031-11041, 2019.

Zhang, N., Gao, Z., Wang, X., and Chen, Y.: Modeling the impact of urbanization on the local and regional climate in Yangtze

530 River Delta, China, Theoretical and applied climatology, 102(3-4), 331-342, 2010.

531 Zhang, W., Zhuang, G., Guo, J., Xu, D., Wang, W., and Baumgardner, D., et al.: Sources of aerosol as determined from elemental composition and size distributions in Beijing, Atmospheric Research, 95(2-3), 0-209, 2010.

Zhang, Z., Zhao, X., Xiong, Y., et al.: The Fog/Haze Medium-range Forecast Experiments Based on Dynamic Statistic Method, Journal of Applied Meteorological Science (in Chinese), 29(1),57-69, 2018.

Zhao, P., Xu, X., Meng, W. Dong, et al.: Characteristics of haze days in the region of Beijing, Tianjin, and Hebei, China Environmental Science (in Chinese), 31(1), 31-36, 2012.

Zhao, X., Li, Z., and Xu, J.: Beijing regional environmental meteorology prediction system and its performance test of PM2.5 concentration, Journal of Applied Meteorological Science (in Chinese), 27(2), 160-172, 2016.

Zhao, X.J., Li, Z.M., Xu, J.: Modification and performance tests of visibility parameterizations for haze days. Environ. Sci., 40 (4), 1688-1696 (in Chinese), 2019.

Zhong, S., Qian, Y., Sarangi, C., Zhao, C., Leung, R., Wang, H., et al.: Urbanization effect on winter haze in the Yangtze River Delta region of China. Geophysical Research Letters, 45, 6710-6718, https://doi.org/10.1029/2018GL077239, 2018.

Zhong, S., Qian, Y., Zhao, C., Leung, R., \& Yang, X. Q.: A case study of urbanization impact on summer precipitation in the Greater Beijing Metropolitan Area: Urban heat island versus aerosol effects. Journal of Geophysical Research: Atmospheres, 120, 10,903-10,914. https://doi.org/10.1002/2015JD023753, 2015.

Zhong, S., Qian, Y., Zhao, C., Leung, R., Wang, H. L., Yang, B., et al.: Urbanization-induced urban heat island and aerosol effects on climate extremes in the Yangtze River Delta region of China. Atmospheric Chemistry and Physics, 17(8), 54395457, https://doi.org/10.5194/acp-17-5439-2017/, 2017. 


\section{$554 \quad$ Figure}

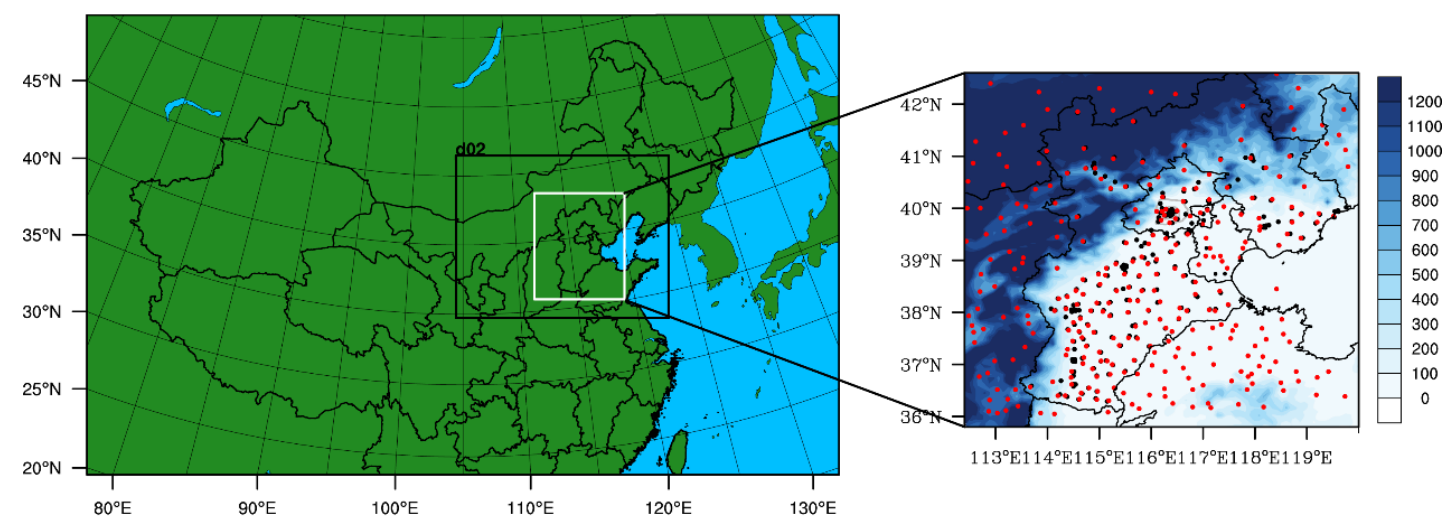

Figure 1 Domain configuration of RMAPS-ST and the location of the study area, indicated by the white solid line. The black dots indicate the locations of the 251 environmental monitoring stations, and the red dots represent the 309 meteorological 
https://doi.org/10.5194/acp-2020-303

Preprint. Discussion started: 14 April 2020

(c) Author(s) 2020. CC BY 4.0 License.

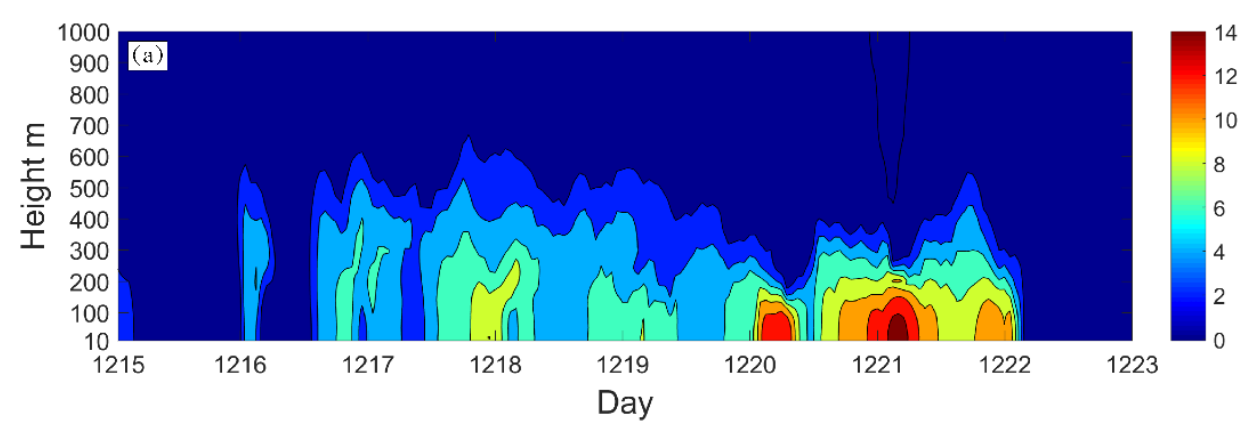

561

Figure 2 (a) Hourly backscattering coefficient (shading; $\left.\mathrm{mm} \cdot \mathrm{sr}^{-1}\right)$ observed by single-lens ceilometers $\left(39.97^{\circ} \mathrm{N}, 116.37^{\circ} \mathrm{E}\right)$

564 from the $15^{\text {th }}$ to $23^{\text {rd }}$ of December; (b) hourly column backscatter coefficient (black line; $\mathrm{sr}^{-1}$ ) and AOD used in modeling for Beijing (blue line) and (c) their correlations. 

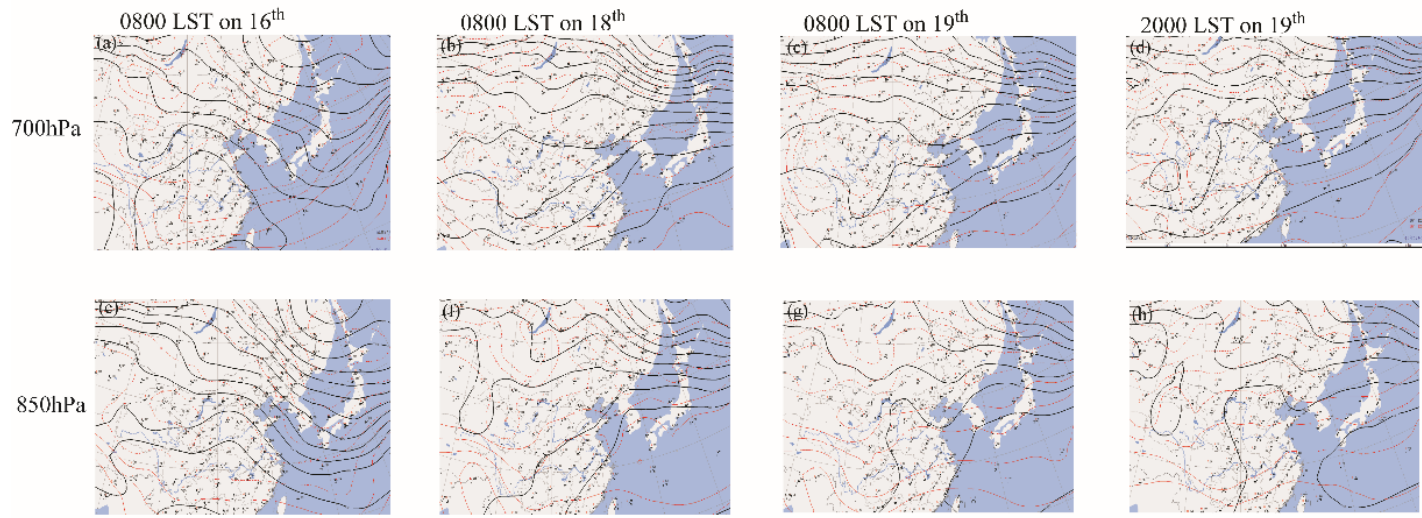

Figure 3 Weather maps. (a) $0800 \mathrm{LST}$ on the $16^{\text {th }}$ at $700 \mathrm{hPa}$; (b) $0800 \mathrm{LST}$ on the $18^{\text {th }}$ at $700 \mathrm{hPa}$; (c) $0800 \mathrm{LST}$ on the $19^{\text {th }}$ at $700 \mathrm{hPa}$; (d) $2000 \mathrm{LST}$ on the $19^{\text {th }}$ at $700 \mathrm{hPa}$; (e) $0800 \mathrm{LST}$ on the $16^{\text {th }}$ at $850 \mathrm{hPa}$; (f) $800 \mathrm{LST}$ on the $18^{\text {th }}$ at $850 \mathrm{hPa}$; (g) $0800 \mathrm{LST}$ on the $19^{\text {th }}$ at $850 \mathrm{hPa}$; (h) $2000 \mathrm{LST}$ on the $19^{\text {th }}$ at $850 \mathrm{hPa}$.

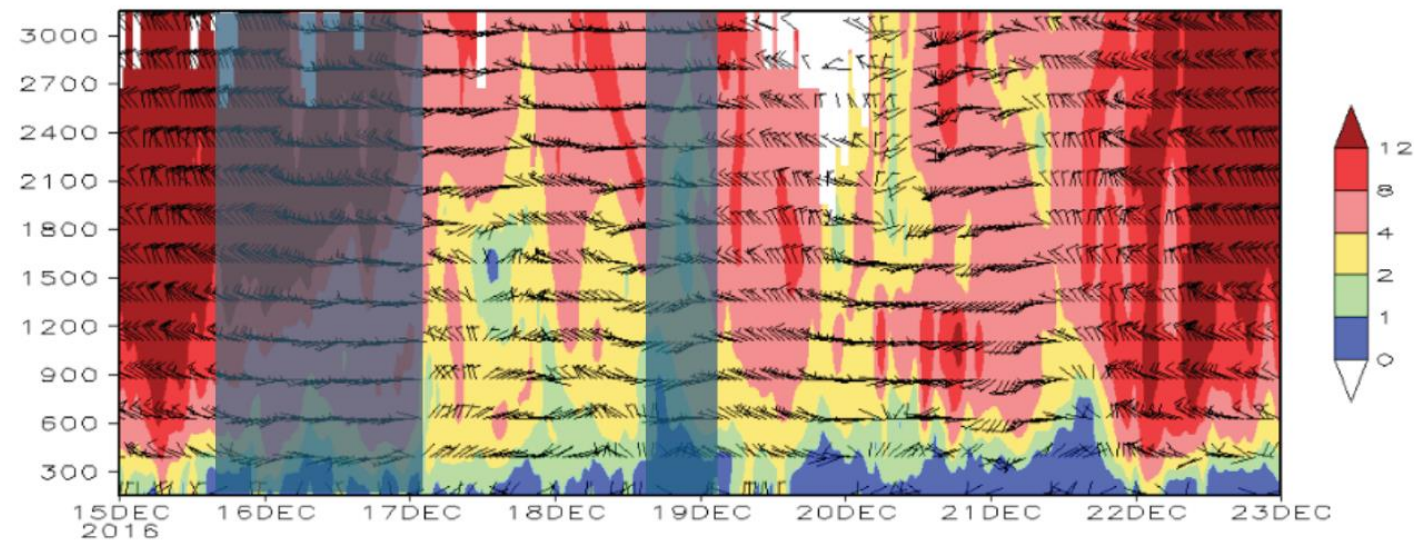

Figure 4 Hourly wind profile from the $15^{\text {th }}$ to $23^{\text {rd }}$ of December. Wind speed (shading; $\mathrm{m} \cdot \mathrm{s}^{-1}$ ) and horizontal wind field (vector; $\left.\mathrm{m} \cdot \mathrm{s}^{-1}\right)$. The shaded parts show the two periods of south wind conveyance. 

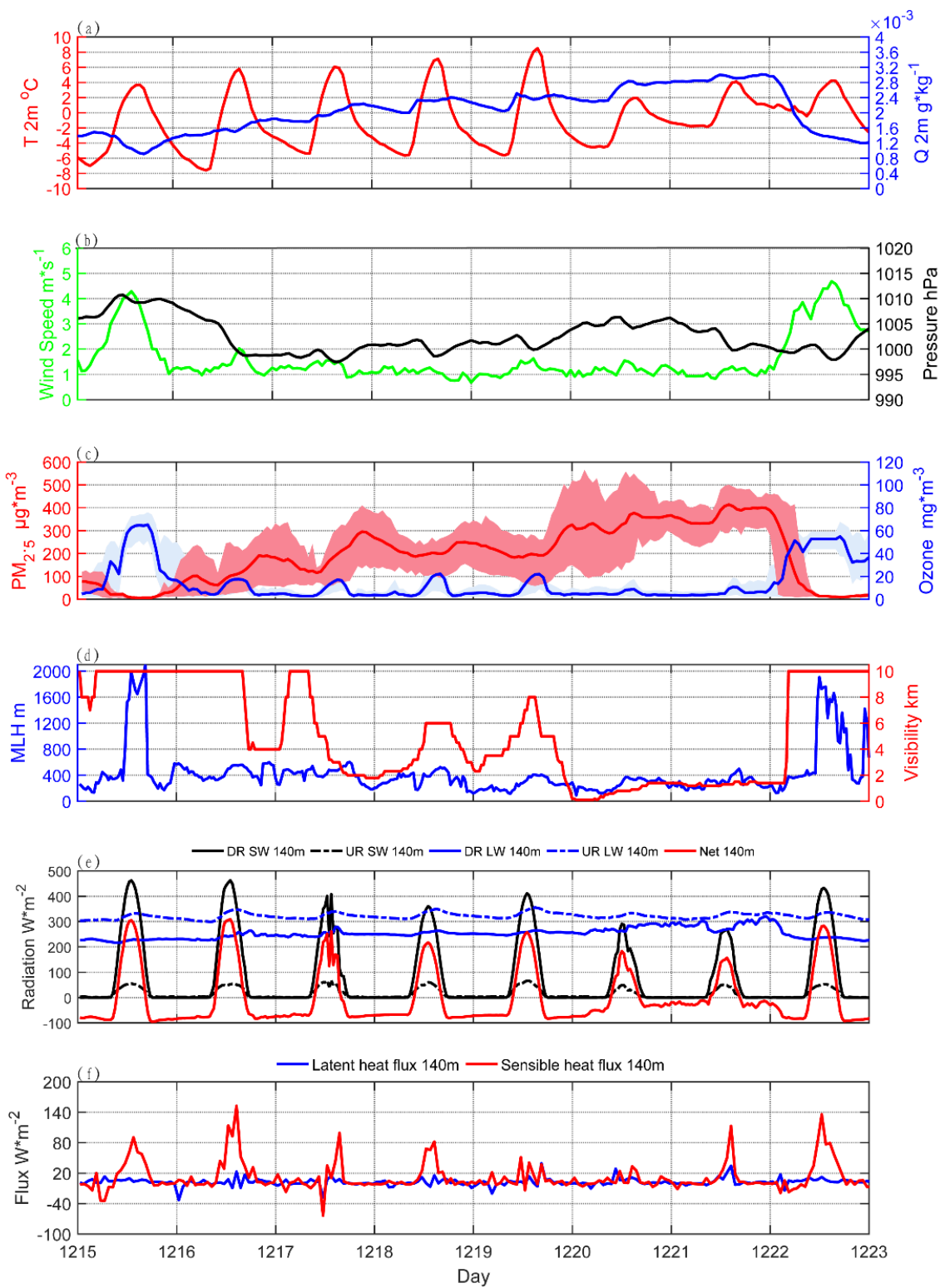

Figure 5 Diurnal pattern of observed variables from the $15^{\text {th }}$ to $23^{\text {rd }}$ of December in Beijing. (a) Temperature (red line; ${ }^{\circ} \mathrm{C}$ ) and absolute humidity (blue line; $\mathrm{g} \cdot \mathrm{kg}^{-1}$ ) at $2 \mathrm{~m}$; (b) wind speed at $10 \mathrm{~m}$ (green line; $\mathrm{m} \cdot \mathrm{s}^{-1}$ ) and pressure (black line; hPa); (c) average $\mathrm{PM}_{2.5}$ concentration (red line is the average and the shading indicates the standard deviation; ug. $\mathrm{m}^{-3}$ ) and ozone concentration (blue lines and the shading indicate the standard deviation; $\mathrm{mg} \cdot \mathrm{m}^{-3}$ ) of 35 environmental monitoring stations in Beijing; (d) mixing layer height (blue line; $\mathrm{m}$ ) and visibility (red line; $\mathrm{km}$ ); (e) radiation from the observation tower at $140 \mathrm{~m}$, downward shortwave radiation (solid black line; $\mathrm{W} \cdot \mathrm{m}^{-2}$ ), upward shortwave radiation (dashed black line; $\mathrm{W} \cdot \mathrm{m}^{-2}$ ), downward longwave radiation (solid blue line; $\mathrm{W} \cdot \mathrm{m}^{-2}$ ), upward longwave radiation (dashed blue line; $\mathrm{W} \cdot \mathrm{m}^{-2}$ ), net radiation (red line; $\mathrm{W} \cdot \mathrm{m}^{-2}$ ); and (f) sensible heat flux (red line; $\mathrm{W} \cdot \mathrm{m}^{-2}$ ) and latent flux (red line; $\mathrm{W} \cdot \mathrm{m}^{-2}$ ). 

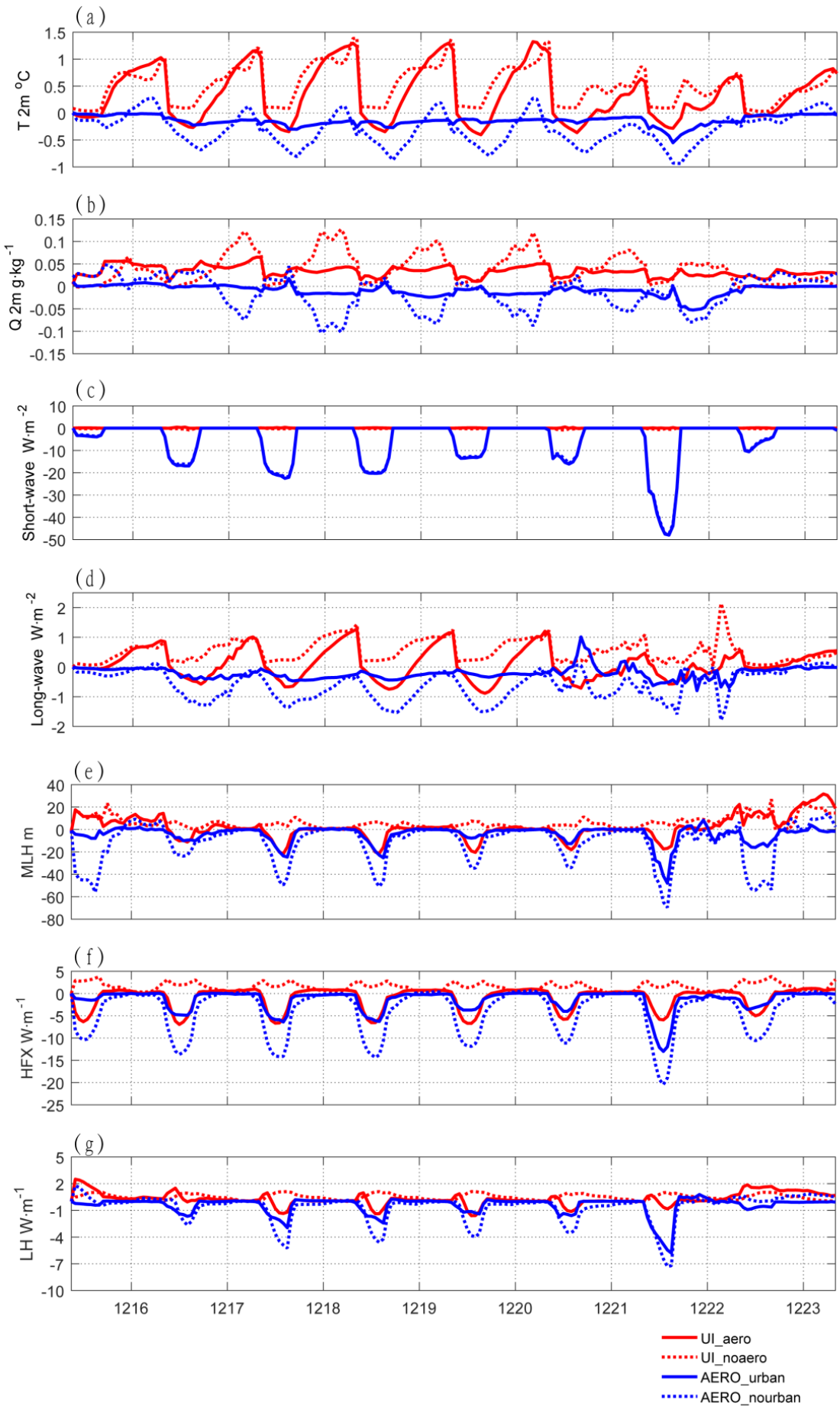

Figure 6 Diurnal pattern of the simulated variable from the $15^{\text {th }}$ to $23^{\text {rd }}$ of December. (a) Temperature at $2 \mathrm{~m}\left({ }^{\circ} \mathrm{C}\right)$; (b) specific humidity $\left(\mathrm{g} \cdot \mathrm{kg}^{-1}\right)$ at $2 \mathrm{~m}$; (c) shortwave radiation $\left(\mathrm{W} \cdot \mathrm{m}^{-2}\right)$; (d) longwave radiation $\left(\mathrm{W} \cdot \mathrm{m}^{-2}\right)$; (e) MLH (m); (f) sensible heat flux $\left(\mathrm{W} \cdot \mathrm{m}^{-2}\right)$; and $(\mathrm{g})$ latent heat flux $\left(\mathrm{W} \cdot \mathrm{m}^{-2}\right)$. 
https://doi.org/10.5194/acp-2020-303

Preprint. Discussion started: 14 April 2020

(C) Author(s) 2020. CC BY 4.0 License.
Atmospheric

Chemistry and Physics

Discussions

590

591

592

593

594

595

596

597
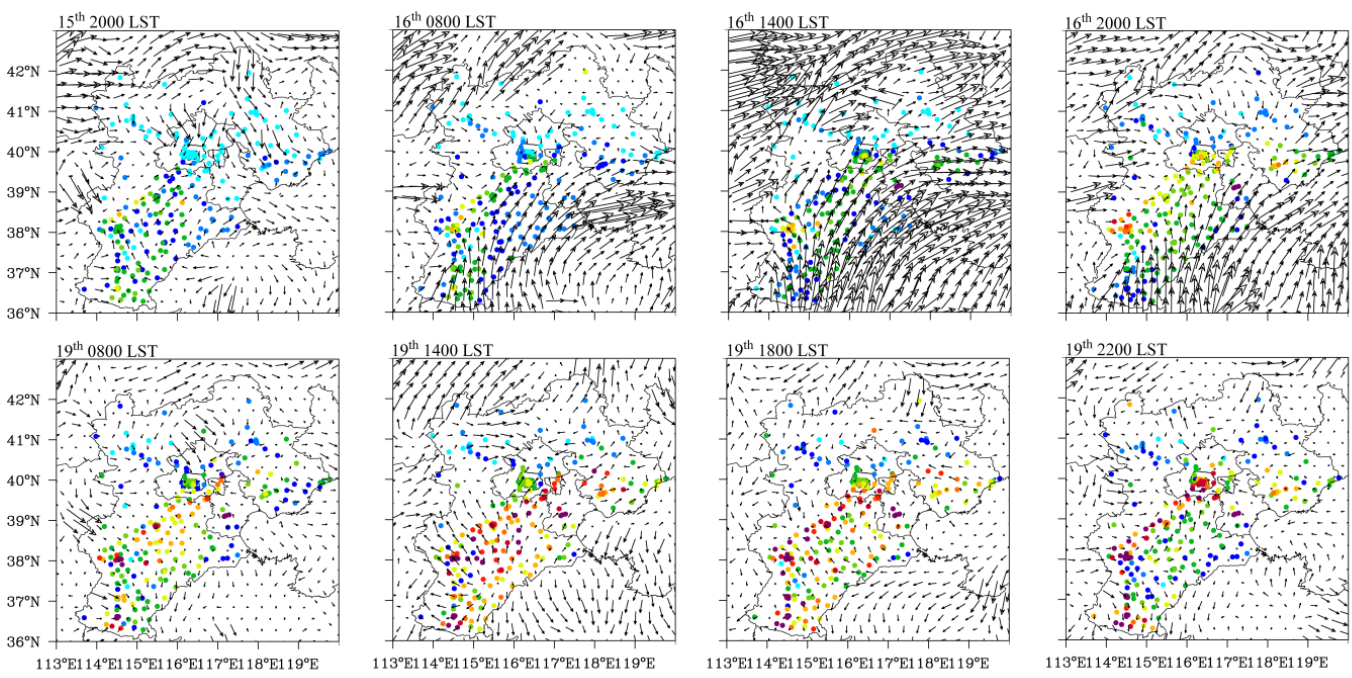

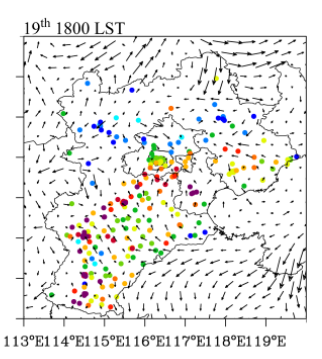

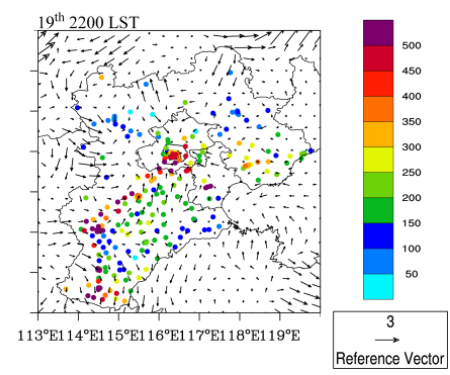

Figure 7 Spatial distribution of the observed concentration of $\mathrm{PM}_{2.5}\left(\right.$ dots; $\mathrm{ug} \cdot \mathrm{m}^{-3}$ ) and wind field (vector; $\mathrm{m} \cdot \mathrm{s}^{-1}$ ) for two increasing processes of the concentration of $\mathrm{PM}_{2.5}$. 
https://doi.org/10.5194/acp-2020-303

Preprint. Discussion started: 14 April 2020

(c) Author(s) 2020. CC BY 4.0 License.
Atmospheric

Chemistry

and Physics

Discussions
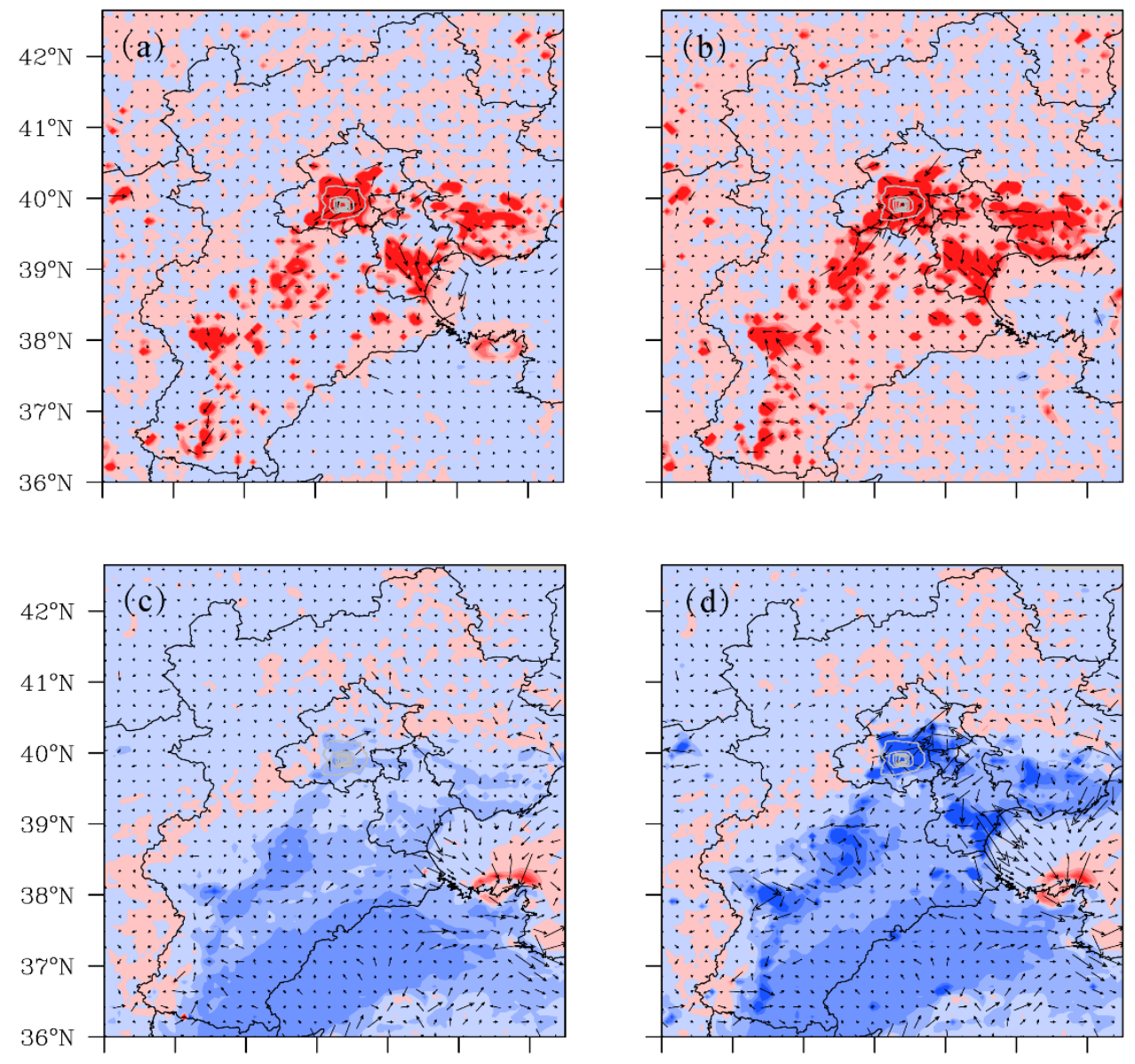

$113^{\circ} \mathrm{E} 14^{\circ} \mathrm{E} 15^{\circ} \mathrm{E} 116^{\circ} \mathrm{E} 11^{\circ} \mathrm{E} 118^{\circ} \mathrm{E} 119^{\circ} \mathrm{E}$

$113^{\circ} \mathrm{E} 114^{\circ} \mathrm{E} 115^{\circ} \mathrm{E} 116^{\circ} \mathrm{E} 117^{\circ} \mathrm{E} 118^{\circ} \mathrm{E} 119^{\circ} \mathrm{E}$
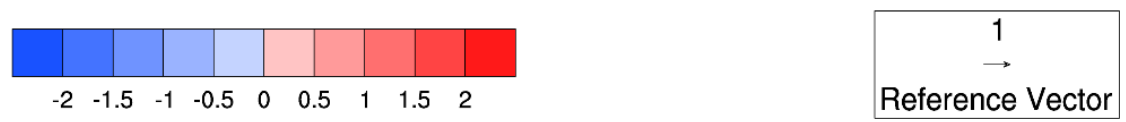

598

599

600

601

602

603
Figure 8 Spatial distribution of simulated temperature (shading; ${ }^{\circ} \mathrm{C}$ ) and wind field (vector; $\mathrm{m} \cdot \mathrm{s}^{-1}$ ). (a) UI_aero; (b) UI_noaero; (c) AI_urban; (d) AI_nourban. 
(b) Absolute humidity in $2 \mathrm{~m}$
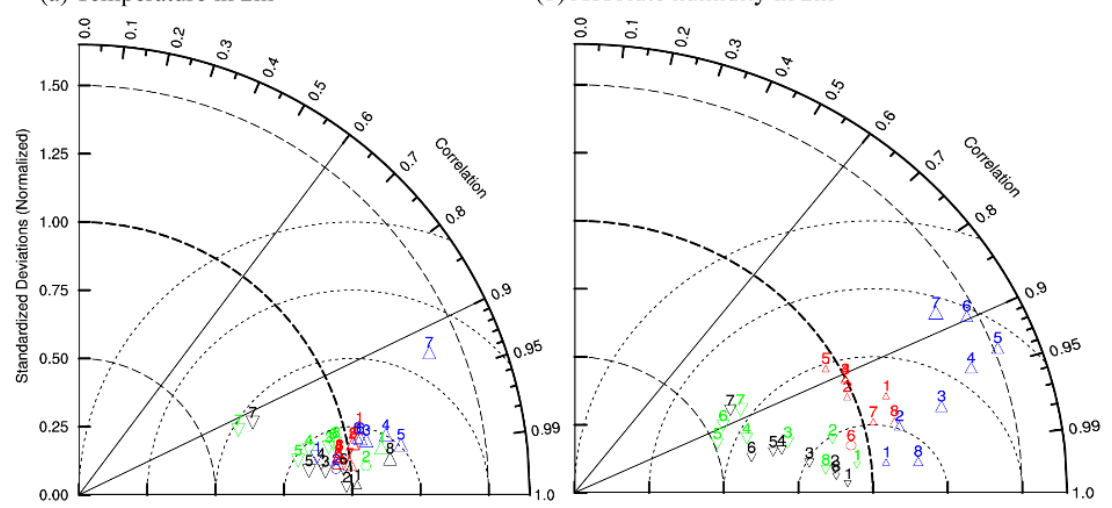

(d) Shortwave radiation
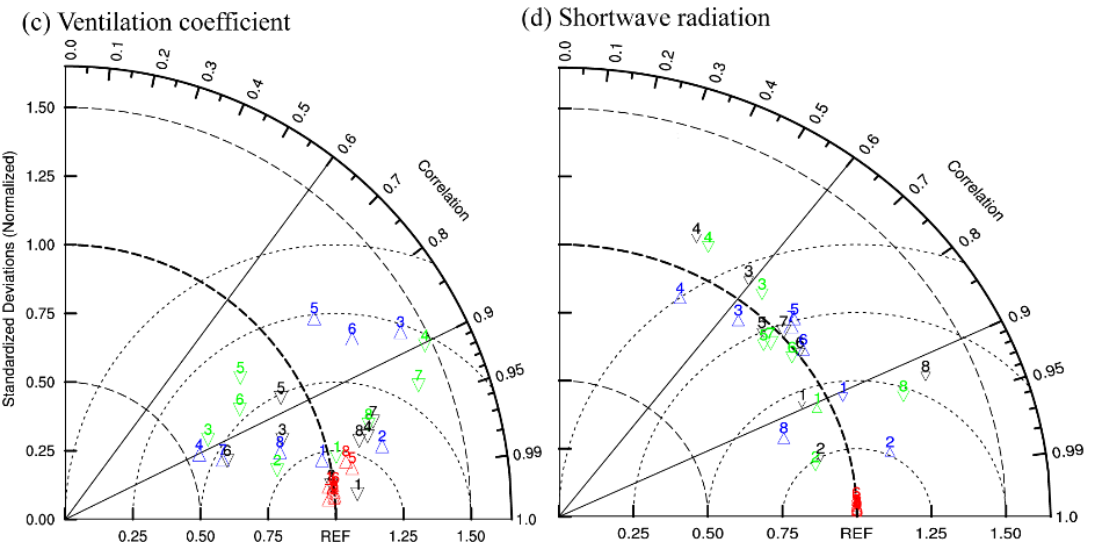

\section{- AI_nourban \\ - Al urban \\ - UI_noaero \\ - UI_aero}

2 - Day 2

3 - Day 3

4 - Day 4

5 - Day 5

6 - Day 6

7 - Day 7

8 - Day 8

Figure 9 Daily means of the four types of impacts (UI_aero, UI_noaero, AI_urban, AI_nourban) in the eight days are shown in Taylor diagrams in the Beijing area. (a) Temperature at $2 \mathrm{~m}\left({ }^{\circ} \mathrm{C}\right)$; (b) absolute humidity $\left(\mathrm{g} \cdot \mathrm{kg}^{-1}\right)$; (c) ventilation coefficient $\left(\mathrm{m}^{2} \cdot \mathrm{s}^{-1}\right) ;(\mathrm{d})$ shortwave radiation $\left(\mathrm{W} \cdot \mathrm{m}^{-2}\right)$. 

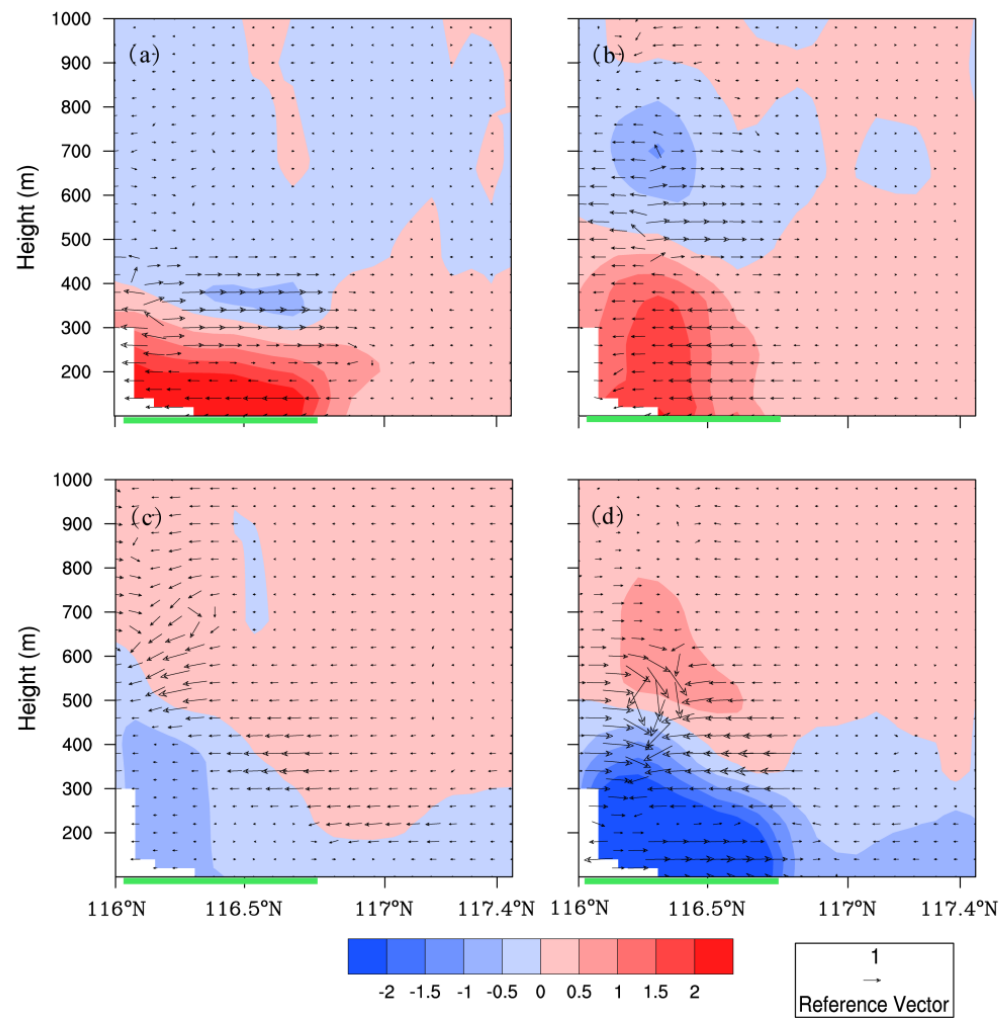